\title{
STRESS ANALYSIS ON STEERING KNUCKLE OF THE AUTOMOBILE STEERING SYSTEM
}

\author{
B.Babu' ${ }^{1}$ M. Prabhu ${ }^{2}$, P.Dharmaraj ${ }^{3}$, R.Sampath ${ }^{4}$ \\ ${ }^{1} P G$ Scholar, Manufacturing Engineering, Karpagam University, Coimbatore, Tamilnadu, India \\ ${ }^{2}$ Assistant Professor, Mechanical Engineering, kathircollege of Engineering, Coimbatore, Tamilnadu, India \\ ${ }^{3}$ Assistant Professor, Mechanical Engineering, kathircollege of Engineering, Coimbatore, Tamilnadu, India \\ ${ }^{4} P G$ Scholar, Thermal Engineering, RVScollege of engineering and technology, Coimbatore, Tamilnadu, India
}

\begin{abstract}
Steering Knuckle plays major role in many direction control of the vehicle it is also linked with other linkages and supports the vertical weight of the car. Therefore, it requires high precision, quality, and durability. The main objective of this work is to explore performance opportunities, in the design and production of a steering knuckle. This can be achieved by performing a detailed load analysis. Therefore, this study has been dealt with two steps. First part of the study involves modeling of the steering knuckle with the design parameters using the latest modeling software, and also it includes the determination of loads acting on the steering knuckle as a function of time. This is done for finding out the minimum stress area. Then the stress analysis was performed using analysis software. The steering knuckle can be modeled, and analyzed under the actual load conditions. This may also improve the depth knowledge of its function and performance in terms of durability and quality.
\end{abstract}

Keywords: Steering knuckle, stress analysis and Finite Element Analysis (FEA). $* * *$

\section{INTRODUCTION}

\subsection{Introduction to Steering Knuckle}

The steering knuckle is the connection between the tie rod, stub axle and axle housing. Steering knuckle is connected to the axle housing by using king pin. Another end is connected to the tie rod. Then the wheel hub is fixed over the knuckle using a bearing. The function of the steering knuckle is to convert linear motion of the tie rod into angular motion of the stub axle.

The lighter steering knuckle resulting greater power and less the vibration because of the inertia is less. The steering knuckle carries the power thrust from tie rod to the stub axle and hence it must be very strong, rigid and also as light as possible. In the case of automobile vehicle, during steering and turning the steering knuckle is subjected to compressive and tension loads and due to the wheel rotation it is also subjected to torsional load.

Steering knuckle for automobile applications is typically manufactured either by forging or from casting. However, castings could have blow-holes which are detrimental from durability and fatigue points of view. The fact that forgings produce blow-hole-free and better parts gives them an advantage over cast parts.

Due to its large volume production, it is only logical that optimization of the steering knuckle for its weight or volume will result in large-scale savings. It can also achieve the objective of reducing the weight of the vehicle component, thus reducing inertia loads, reducing vehicle weight and improving vehicle performance and fuel economy.

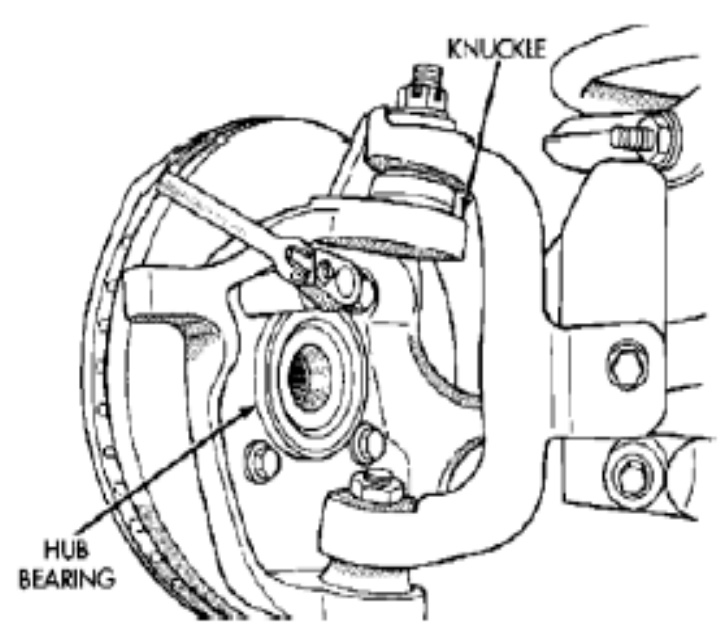

Fig 1 Steering Knuckle with the Wheel Hub

\subsection{Overall Objectives}

\subsubsection{Modeling of the Steering Knuckle}

Modeling of the steering knuckles using a 3D modeling software with its standard dimensions 


\subsubsection{Analysis}

Perform load analysis.

\section{PROBLEM DEFINITION}

As today's automobile vehicle, required to have higher speed and power, their steering knuckle have higher strength and stiffness, but must be lighter in weight and size. In developing power output vehicle, importance is placed on the weight of the linier and angular parts steering arm, tie rod, pitman arm etc. The overall performance of the steering system is affected by higher inertia forces, generated by the moving parts of the vehicle. Therefore, it should always be investigated to avoid any failure of the vehicle in the long run.

The following are the main problems which are found in the manufacturing of the knuckle:

i. Due to uneven stress distribution over steering knuckle, its life reduces.

ii. This affects the overall performance of an automobile vehicle.

iii. Due to the lack of knowledge of stress distribution the material wastage may occur.

\section{DESIGN METHODOLOGY}

\subsection{Analytical Evaluations}

- $\quad$ Digitizing steering knuckle geometry

- $\quad$ Stress (FEA) Analysis

- Modal Analysis

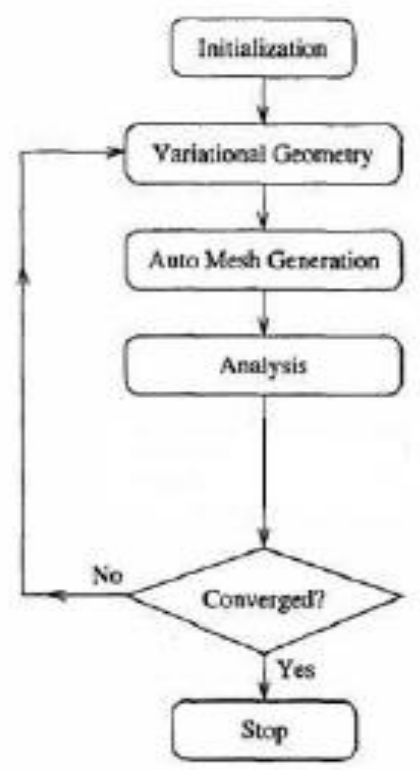

Fig 2 Analysis Flow Chart

\subsection{Steps Involved in Methodology}

Step 1: Modeling of steering knuckle using 3D modeling software.

Step 2: Finite element modeling of the steering knuckle.

Step 3: Analysis of steering knuckle using CATIA software.

i. Element selection.

ii. Discretization.

iii. Mesh generation.

Step 4: Finite element stress analysis.

Step 5: Modal analysis.

\section{DESIGN OF STEERING KNUCKLE}

\subsection{Calculation of Load}

\subsubsection{Axial Loads}

The two major loads acting on the knuckle are Tensile and Compressive loads. The stresses due to these loads can be determined using the following formulas

$$
\text { Tensile Load }\left(\mathrm{P}_{\mathrm{t}}\right)=\text { Tensile Stress } \mathrm{X} \text { Area }
$$

Compressive Load $\left(\mathrm{P}_{\mathrm{c}}\right)=$ Compressive Stress X Area

\subsubsection{Inertia Load}

This load is due to the inertia of the moving parts. To calculate the inertia force, first two harmonies are taken into consideration. It is given by,

$$
\text { Inertia load } \left.\left(\mathrm{F}_{\mathrm{a}}\right)={ }^{\omega^{2} R\left(\cos \theta+R / L_{L} \cos (2 \theta)\right.}\right)^{\prime}
$$

\subsubsection{Bending Load}

This load is due to the weight of the vehicle which is acting on the knuckle. This force trends to bend the steering knuckle outwards, away from the centre line. It is alternating one, and at high speed, it is considerable.

Total inertia bending force is given by

$$
F_{b}=\frac{\rho A_{i} L^{2} \sin (\theta+\phi)}{2} N
$$

\subsection{Calculation of Stresses}

\subsubsection{Stress due to Axial Loads}

These stresses are calculated as follows,

\subsubsection{Stress due to Inertia Bending Force}

Inertia bending load sets up a stress which would be tensile on one side of the knuckle and compressive on another side and that these stresses change sign each half revolution. The 
bending moment at any section ' $\mathrm{x}$ ' $\mathrm{m}$ from the small end is given by

$$
\mathbf{M}=\frac{x}{3}\left[1-\frac{x^{2}}{I^{2}}\right] F
$$

The stress is calculated by using the formula,

$$
\begin{gathered}
\sigma_{b}=M / Z \\
Z=I /(2.5 \times t) \\
I=419 \times t^{4}
\end{gathered}
$$

\section{FINITE ELEMENT ANALYSIS OF THE STEERING KNUCKLE}

\subsection{Analysis Procedure}

\subsubsection{Static Analysis}

A static analysis calculates the effects of steady loading conditions on a structure, while ignoring inertia and damping effects such as those caused by time varying loads.A static analysis can, however, include steady inertia loads such as gravity and rotational velocity, and time - varying loads that can be approximated as static equivalent loads.

\subsubsection{LOADS IN A STATIC ANALYSIS}

Static analysis is used to determine the displacements, stresses, strains, and forces in structures or components caused by loads that do not induce significant inertia and damping effects.

Steady loading and response conditions are assumed that is, the loads and the structure's response are assumed to vary slowly with respect to time. The kinds of loading that can be applied in a static analysis include:

$>$ Externally applied forces and pressures

$>$ Steady- state inertial forces (such as gravity and rotational velocity)

$>$ Imposed (non-zero) displacements

$>$ Temperatures (for thermal strain)

\subsection{Procedure for A Static Analysis}

The procedure for a static analysis consists of three main steps. The overall equilibrium equations for linear structural static analysis are:

1. Build the model

2. Apply loads and obtain the solution

3. Review the results

$$
[\mathbf{K}]\{\mathbf{u}\}=\{\mathbf{F}\}
$$

4. Build the model:

To build the model, define the element types, element real constants, material properties, and the model geometry.

5. Apply loads and obtain the solution:

In this step, the loads (boundary conditions) are defined and the solution is obtained.

6. Review the results:

After the solution is completed, the post-processing step gives the results of the static analysis.

$\checkmark$ Primary data available

$\checkmark$ Nodal displacements (UX, UY, UZ, ROTX, ROTY, ROTZ)

$\checkmark$ Derived data available

$\checkmark \quad$ Nodal and element stresses

$\checkmark \quad$ Nodal and element strains

$\checkmark$ Element forces

$\checkmark$ Nodal reaction forces Etc.,

\subsection{METHODOLOGY}

Following are the process by which the analyzing processes of steering knuckle is done.

$>$ Modeling using CATIA

$>$ Importing to CATIA Workbench

$>$ Generating Meshing

$>$ Applying material properties

$>$ Plotting the result

\subsubsection{Modeling of the Steering Knuckle}

The modelling is done using CATIA with the help of standard dimensions that we got through the careful review. The Catia is one of the famous modelling software available in the market which enables us not only to do the modelling of the components but also the analysis of the same. Hence it is one of the ideal software for modelling and analysis problems. The following diagram is the model of the steering knuckle which is created using the Catia Software.

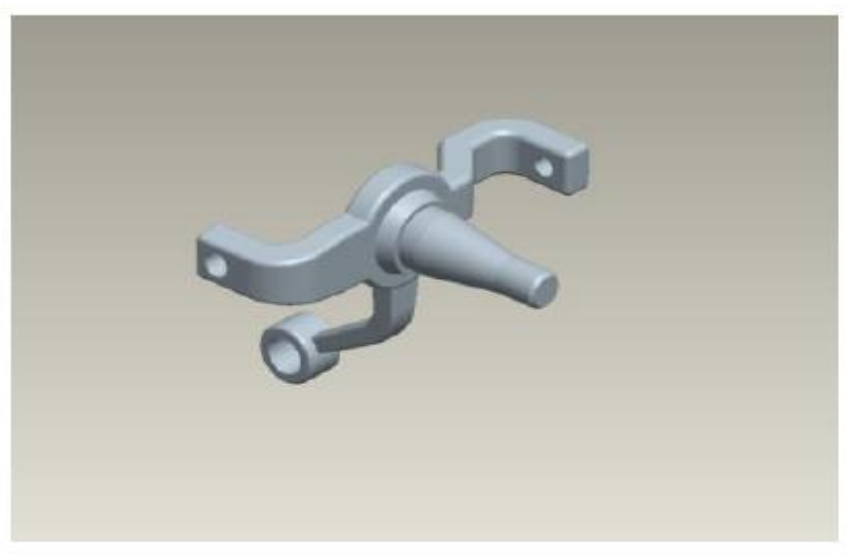

Fig 3 Model of the Steering Knuckle 


\subsubsection{Meshing the Model}

The process for generating a mesh of nodes and elements consists of three general steps:

- $\quad$ CATIA offers a large number of mesh controls from which you can choose as needs dictate.

- Set the element attributes.

- $\quad$ Set mesh controls (optional).

It is not always necessary to set mesh controls because the default mesh controls are appropriate for many models. If no controls are specified, the program will use the default settings to produce a free mesh. Alternatively, you can use the Smart Size feature to produce a better quality free mesh.

\section{RESULTS}

The results are plotted in the form of contour plot for stress distribution as shown in the figure.

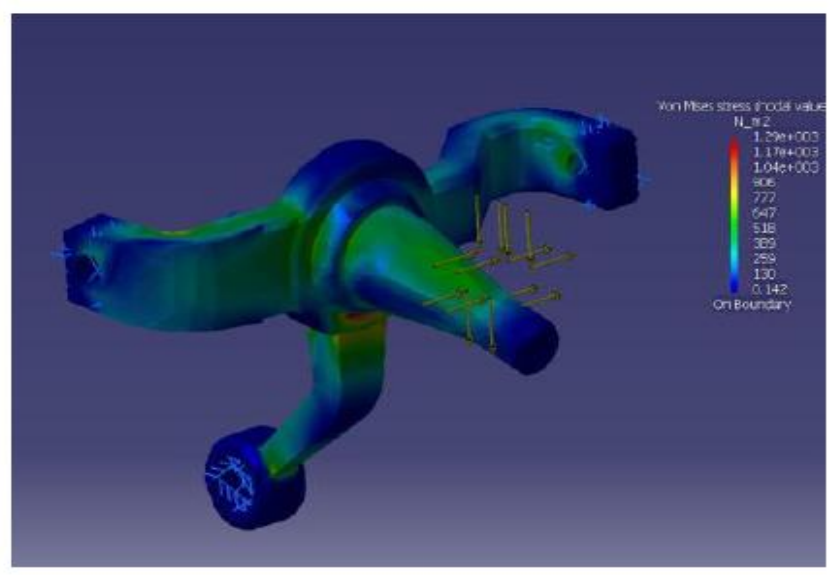

Fig 4 Von Mises Stress Value

\section{CONCLUSIONS}

The steering knuckle has been modeled and analyzed using Catia. The various parameters such as Nodal displacements, Stress distribution are completely analyzed and studied. This study shows that the areas where the stress concentration is maximum due to the applied load and the portions that has to considered in the design of steering knuckle in order to avoid frequent failures to improve its reliability.

\section{REFERENCES}

[1]. Athavale, S. and Sajanpawar, P. R., 1991, "Studies on Some Modelling Aspects in the Finite Element Analysis of Small Gasoline Engine Components," Small Engine Technology Conference Proceedings, Society of Automotive Engineers of Japan, Tokyo, PP. 379-389.

[2]. Farzin h. Montazersadgh and Ali Fatemi, 2007, "Dynamic Load and Stress Analysis of a Crankshaft", SAE International.

[3]. A. Fuganti and G. Cupitò, 2000, "Thixoforming of aluminium alloy for weight saving of a suspension steering knuckle'Italy, 2000.

[4]. R. L. Jhala, K. D. Kothari and S.S. Khandare , 2009, "Component Fatigue Behaviors And Life Predictions Of A Steering Knuckle Using Finite Element Analysis" Proceedings of the International MultiConferenceofEngineers.

[5]. Computer Scientists 2009 Vol II, IMECS 2009, March 18 - 20, 2009, Hong Kong.

[6]. Lee, S. B., "Structural Fatigue Tests of Automobile Components under Constant Amplitude Loadings," Fatigue Life Analysis and Prediction, Proceedings, International Conference and Exposition on Fatigue, Goel, V. S., Ed., American Society of Metals, 1986, pp. 177-186.

[7]. Rice, R. C., ed., 1997, "SAE Fatigue Design Handbook", Society of Automotive Engineers, Warrendale, 3rd Edition.

[8]. Savaidis, G., "Analysis of Fatigue Behavior of a Vehicle Axle Steering Arm Based on Local Stresses and Strains," Material wissenschaft und Werkstoff technik, Vol. 32, No. 4, 2001, pp. 362, 368.

\section{BIOGRAPHIES}

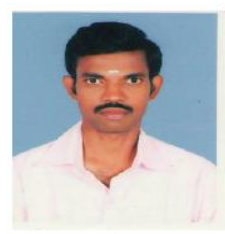

in International
B. Babu is currently pursuing M.E programme from Karpagam University, Coimbatore, India. $\mathrm{He}$ is currently Assistant professor in Department of mechanical engineering, KathirCollege of engineering. He has published 06 papers national/international conference. e-mail-babuamr11@gmail.com

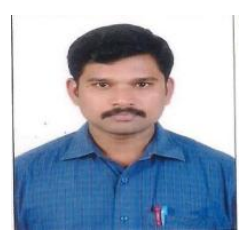

M.PRABHU is currently Assistant professor in Department of mechanical engineering, Kathir College of engineering. He has published 04 papers in International journals and 7 papers in national/international conference.

e-mail-prabhumechanical.m@gmail.com

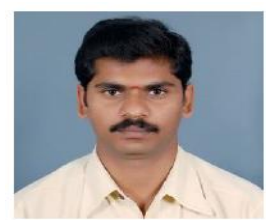

P. Dharamaraj is currently Assistant professor in Department of mechanical engineering, Kathir College of engineering. He has published 04 papers in International journals and 7 papers in national/international conference.

e-mail-dharmarajmeap@gmail.com

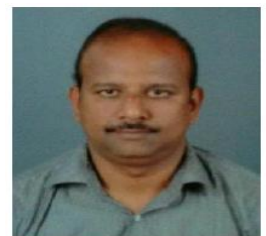

R. Sampath is currently pursuing M.E programme from Rvs college of engineering and technology, Coimbatore. He has published 02 papers in International journals and 4 papers in national/international conference.

e-mail-arangasampath@gmail.com 